\title{
Late Onset Linear Sclorederma
}

\author{
Geç Başlangıçlı Lineer Skleroderma
}

$\dot{I}_{\text {smet Sevimli }}{ }^{l}$, Perihan Öztürk ${ }^{* 1}$, Mehmet Kamil Mülayım ${ }^{1}$, Hülya Nazik ${ }^{l}$

\begin{abstract}
En coup de sabre (linear scleroderma of face) is a rare type of morphea (localized scleroderma) involving frontoparietal area of the forehead and scalp. Many triggering factors have been blamed in the development of morfea like trauma, immobilization, BCG vaccination, injections of vitamin $\mathrm{K}$, mechanical compression from clothing, etc. En coup de sabre usually affects the pediatric population, with $67 \%$ of patients diagnosed before 18 years of age. In this article, it was reported to emphasize the late started a case of 30 years old female.
\end{abstract}

Key words: En coup de sabre, localized scleroderma, morphea

\section{ÖZET}

En coup de sabre (yüzün lineer skleroderması), alın ve saçlı derinin frontopariyetal bölgesini tutan, morfeanın (lineer skleroderma) nadir görülen bir tipidir. Gelişiminde travma, immobilizasyon, BCG aşısı, $\mathrm{K}$ vitamini enjeksiyonları, giysilerin mekanik basısı gibi tetikleyiciler suçlanmıştır. En coup de sabre genellikle pediatrik popülasyonda görülür, olguların \%67'si 18 yaşından önce tanı almıştır. Burada, 30 yaşında yetişkin bir hastaki en coup de sabre geç başlangıcı vurgulamak amacıyla sunulmuştur.

Anahtar kelimeler: En coup de sabre, lokalize skleroderma, morfea, geç başlangıç

Received Date/ Geliş Tarihi: 15.07.2017, Accepted Date/ Kabul Tarihi: 05.02.2018

${ }^{1}$ KSU (Kahramanmaraş Sütçü İmam Üniversitesi) Tip Fakültesi Dermatoloji AB Kahramanmaraş TÜRKiYE

*Address for Correspondence / Yazışma Adresi: perihan öztürk, KSU (Kahramanmaraş Sütçü İmam Üniversitesi )Tıp Fakültesi

Dermatoloji AB Kahramanmaraş TÜRKIYE

E-mail: drperihanozturk@hotmail.com

Sevimli İ, Öztürk P, Mülayım MK, Nazik H. Geç Başlangıçlı Lineer Skleroderma. TJFMPC, 2018; 12(2): 153-155.

DOI: $10.21763 / \mathrm{tjfmpc.432556}$ 


\section{GíRiş}

Skleroderma; deride ve diğer organlarda artmış kollajen üretimine bağlı kalınlaşma ve sertleşmelerle karakterize olan, etiyolojisi bilinmeyen bir bağ dokusu hastalığıdır. Lokalize skleroderma ile sistemik sklerozis arasında yer alan geniş bir dağılıma sahiptir. ${ }^{1}$ Morfea olarak bilinen lokalize formu iç organ tutulumu olmaksızın deriyi, nadiren de deri altı kas dokusunu tutar. ${ }^{2}$ Morfea lineer skleroderma, plak morfea, derin morfea, büllöz morfea ve generalize morfea olarak alt tiplere ayrilır. ${ }^{3-5}$ Lineer skleroderma çoğu zaman ekstremitelerde yerleşir fakat bazen alın ve saçlı derinin frontoparyetal bölgesini de tutabilir ki bu durum kılıç yarasına benzediği için en coup de sabre olarak adlandırılmıştır. ${ }^{6}$ En coup de sabre çocuklarda yaklaşık 10 yaş civarında sık görülmekle birlikte yetişkinlerde nadirdir. ${ }^{7,8} \mathrm{Bu}$ çalışmada, geç başlangıçlı bir en coup de sabre olgusu sunulmuştur.

\section{OLGU SUNUMU}

30 yaşındaki kadın hasta, alın sol frontal bölgeden sol kaşa doğru uzanan lineer plak sebebiyle polikliniğimize başvurdu. Öyküsünde şikayetinin yaklaşık 3 yıl önce başladığı öğrenildi. 1 y1l önce yapılan biyopsisinde; kollajenize bağ dokuda artış ve kollajende kabalaşma, histokimyasal trikrom boyası ile kollajende artış, elastik boyasında elastik liflerde dejenerasyon görülmüş olup morfea ile uyumlu rapor edilmişti.

Olgunun öz geçmişinde ve soy geçmişinde bir özellik yoktu.

Olgunun dermatolojik muayenesinde alın sol taraf saçlı deriden sol kaşa doğru uzanan lineer hafif deprese bir plak mevcuttu (Resim 1). Palpasyonda hafif sertlik hissedilmekteydi.

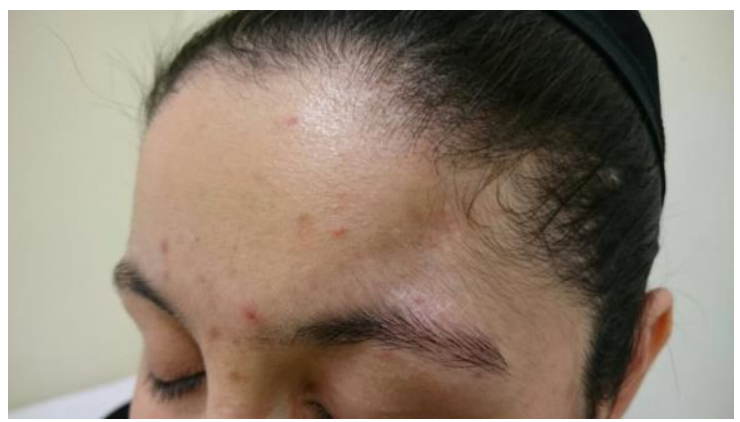

Resim 1. Alın sol taraf saçlı deriden sol kaşa doğru uzanan lineer hafif deprese plak

Olgu eşlik edebilecek nörolojik anomaliler açısından göz ve nöroloji polikliniğine yönlendirildi. Herhangi bir patoloji saptanmadı.
Sekiz ay boyunca kullandığı kolşisine rağmen şikayetlerinde gerileme olmayan hastaya metotreksat $7,5 \mathrm{mg}$ tablet, topikal kalsipotriol ve betametazon krem, topikal takrolimus \% 0,1 pomat başland1. 1. ay kontrolünde hastanın endürasyonunda azalma olduğu tespit edildi.

\section{TARTIŞMA}

Skleroderma derinin fibrozisine neden olan bir hastalıktır. Sadece deri tutulumu ile sinırlı olabileceği gibi iç organ tutulumunun da eşlik ettiği daha ciddi hastalık formlarında da görülebilir. Skleroderma, sistemik sklerozis ve lokalize skleroderma olarak iki majör gruba ayrılır. Lokalize skleroderma yalnızca deri ve deri altı dokuya sınırlıdır ve Raynaud fenomeni, akroskleroz ve iç organ tutulumunun olmaması ile sistemik formdan ayrılır. ${ }^{4}$ Lokalize sklerodermanın bir alt tipi olan lineer skleroderma genellikle çocuklarda görülür. Lineer sklerodermalı hastaların \% 67'si 18 yaşından önce tanı almıştır. ${ }^{6}$ Literatürde yetişkin başlangıçlı olgu sayısı nadir olup Arif ve ark. 26 yaşında başlayan lineer skleroderma olgusu sunulmuştur. ${ }^{9}$ Olgumuzda 27 yaşında bir başlangıç söz konusuydu.

Morfeanın kesin sebebi bilinmemekle birlikte; patojenik süreçlerin başında iki olası sebep ileri sürülmektedir: fibroblast fonksiyon bozukluğu ve olgularda daha fazla otoimmün hastalıklar görüldüğü için otoimmün fonksiyon bozukluğu; bununla birlikte; literatürde travma, immobilizasyon, BCG aşısı, $\mathrm{K}$ vitamini enjeksiyonları ve giysilerin mekanik basısı tetikleyici faktörler olarak düşünülmüştür. ${ }^{10,11,12}$ Olguda herhangi bir travma ve enjeksiyon öyküsü bulunmamaktayd1.

Vakaların çoğu sporadiktir. Bununla birlikte ailesel vakalarda rapor edilmiştir. Ailesel olguların belirgin HLA birlikteliklerinden ziyade, ortak tetikleyicilere maruziyetten dolayı oluştuğu bildirilmiştir. ${ }^{13}$

Her ne kadar kesin mekanizmaları açık değilse de lokalize skleroderma, en coup de sabre ve sistemik sklerozisin patogenezinin benzer olduğu düşünülür. ${ }^{10}$ Erken dönemdeki deri biyopsileri aylar veya y1llar sonrası fibrozis gelişiminden önce endotelyal hücre hasarını gösterir. Sonrası, mononükleer hücre infiltratına eşlik eden vasküler permeabilite artışı perivasküler hücre infiltratına, damar duvarı intimasının kalınlaşmasına ve vasküler lümenin daralmasına yol açar. ${ }^{14}$ Mikrovasküler hasara neyin sebep olduğu ise tam anlaşılamamakla birlikte çocuk popülasyonda gelişim öncesi travma suçlanmıştır. ${ }^{15}$ Olgumuzda tetikleyici etken tespit edilemedi. 
En coup de sabre, nörolojik anomalilere eşlik edebilmektedir. Çayırlı ve arkadaşlarının yaptığı bir çalışmada 22 yaşında bir yetişkin olguda en coup de sabre epilepsi birlikteliği saptanmıştır. ${ }^{16}$ Olgumuzda nörolojik tutulum saptanmadı.

Hastalığın ayrıcı tanısında; liken sklerosus et atrofikus, lupus pannikülit, morfea benzeri fenilketonüri, eozinofilik fasit gibi hastalıklar düşünülmekle birlikte klasik klinik görünüm ile kolayca biyopsi ile de kesin ayrımı yapılabilir. ${ }^{12}$

Literatürde morfea tedavisinde fototerapi, imikimod, topikal takrolimus, kalsipotriol betametazon kombinasyonu, sistemik steroidler ve metotreksat, D-penisilamin, siklosporin, mikofenolat mofetil ve fotoforez gibi çok sayıda tedavi seçeneği kullanılagelmiştir. ${ }^{1}$ Olgumuza metotreksat 7,5 mg tablet, topikal kalsipotriol betametazon kombinasyonu ve topikal takrolimus tedavisi verildi ve 1 ay sonraki kontrolünde hastanın endürasyonda azalma tespit edildi.

En coup de sabre yetişkinlerde nadir görülen lineer sklerodermanın yüz yerleşimli formudur. $\mathrm{Bu}$ çalışma, hem literatürde geç başlangıçlı en coup de sabrenin nadir görülmesi sebebiyle hem de aile hekimliğine başvuran hastalara; hastalıkla ilgili bilgi verilebilmesi, eşlik eden hastalıkların araştırılabilmesi ve erken dönem tedavisinin yapılabilmesini vurgulamak amaciyla sunulmuştur.

\section{KAYNAKLAR}

1. Fett N, Werth WP. Update on morphea: part I. Epidemiology,clinical presentation, and pathogenesis. J Am Acad Dermatol 2011; 64: 217-228.

2. Weibel L, Sampaio MC, Visentin MT, Howell KJ, Woo P, Harper JI. Evaluation of methotrexate and corticosteroids for the treatment of localized scleroderma (morphoea) in children. $\mathrm{Br} \mathrm{J}$ Dermatol 2006; 155:1013-1020.

3. Cassidy JT, Petty RE. The systemic scleroderma and related disorders. In: Cassidy JT, Petty RE, editors. Textbook of pediatric rheumatology. Philadelphia: W. B. Saunders; 2001. p. 505-34.

4. Nelson A. Localized sclerodermas. In: Cassidy JT, Petty, RE, editors. Textbook of pediatric rheumatology. Philadelphia: W. B. Saunders; 2001. p. 535-44.

5. Uziel Y, Miller ML, Laxer RM. Scleroderma in children. Pediatr Clin North Am 1995; 42: 1171-1203.

6. Holland KE, Steffes B, Nocton JJ, Schwabe MJ, Jacobson RD, Drolet BA. Linear scleroderma en coup de sabre with associated neurologic abnormalities. Pediatrics 2006;117:132-136.

7. Tollefson MM, Witman PM. En coup de sabre morphea and Parry-Romberg syndrome: a retrospective review of 54 patients. J Am Acad Dermatol 2007; 56: 257.

8. Orozco-Covarrubias L, Guzmán-Meza A, Ridaura-Sanz C, Carrasco Daza D, Sosade-Martinez C, Ruiz-Maldonado R. Scleroderma 'en coup de sabre' and progressive facial hemiatrophy. Is it possible to differentiate them? J Eur Acad Dermatol Venereol. 2002;16(4):361-6.

9. Goodfield MJD, Jones SK, Veale DJ. The Connective Tissue Diseases. In: Burns T, Breathnach S, Cox N, Griffiths C. Eds. Rook's Textbook of Dermatology. WileyBlackwell, U.K, 8 th. ed 2010;3:51645178.

10. Ehara M, Oono T, Yamasaki O, Matsuura $\mathrm{H}$, Iwatsuki K. Generalized morphea-like lesions arising in mechanicallycompressed areas by underclothes. Eur J Dermatol 2006; 16(3):307-309.

11. Katsumoto TR, Whitfield ML, Connolly MK. The pathogenesis Of systemic sclerosis. Annu Rev Pathol 2011; 6:509-37. doi: 10.1146/annurev-pathol-011110-130312.

12. Zulian F. Localized scleroderma in childhood.

https://www.uptodate.com/contents/locali zed-scleroderma-in-

childhood?sectionName=Linear $\% 20$ scler oderma $\% 20$ of $\% 20$ the $\% 20$ face \&anchor $=$ H10\&source $=$ see_link\#H16

13. Brownell I, Soter NA, Franks Jr, AG. Familial linear scleroderma (en coup de sabre) responsive to antimalarials and narrowband ultraviolet B therapy. Dermatology Online Journal 2007; 13:11.

14. Vancheeswaran R, Black CM, David J,Hasson N, Harper J,Atherton $\mathrm{D}$, et al. Childhood-onset scleroderma: Is it different from adult-onset disease. Arthritis Rheum 1996; 39:1041 9.

15. Arif $\mathrm{T}$, Majid I, Ishtiyaq Haji ML. Late onset 'en coup de sabre' following trauma: Rare presentation of a rare disease. Our Dermatol Online 2015;6:4951.

16. Çayırlı M, Açıkgöz G. Linear scleroderma 'en coup de sabre' and Epilepsy: A case report. J Turk Acad Dermatol 2013;7:137. 